\title{
Analyses of Community Attributes of Meiofauna Under A Pollution Regime in the Lower Bonny Estuary, Rivers State, Nigeria
}

\author{
Iderima S.T ${ }^{1}$, Alagoa K.J ${ }^{2 *}$, Ngodigha S.A ${ }^{3}$ \\ ${ }^{1}$ Institute of Geosciences and Space Technology, Rivers State University of Science and Technology, Port Harcourt, Rivers \\ State, Nigeria. \\ ${ }^{*}$ Department of Biological Sciences, Niger Delta University, Amasoma, Bayelsa State, Nigeria. \\ ${ }^{3}$ Department of Agricultural Education, Isaac Jasper Boro College of Education, Sagbama, Bayelsa State, Nigeria.
}

\begin{abstract}
Meiofauna community attributes of the lower Bonny estuary was investigated under a pollution regime. This is germane because of the strategic importance of meiofauna in the food chain and the sustenance of any aquatic ecosystem. Five stations representing diverse land based activities such as refuse dump site, fuel depot, fishing-landing areas, residential housing and a station located up-stream (control) were chosen for investigation. The meiofauna samples were collected from sediments in three replicate spots per station per sampling months at low tide. Sediment samples were stirred through (63-212nm) meshes to separate meiofauna and organic debris. Meiofauna samples were processed by first washing Meiofauna through a sieve of fine mesh size made of silk material, in order to wash off formation and excess silt or mud. Meiofauna samples were sorted out and identified using standard keys. Result from field studies indicate that meiofauna population abundance and diversity varied slightly between stations and seasons. There was however, no established trend. Meiofauna were generally more abundant in the rainy season than in the dry season. In general, pollution indicator meiofaunal taxa were more in all stations except the control station; the increasing impact of pollutants in the river led to a rise in the relative abundance of $r$-strategist genera like Chromadora. We conclude that the application of meiofaunal indices can be a useful tool for assessing the environmental quality of estuarine ecosystems.
\end{abstract}

Keywords-Community structure, Pollution, Meiofauna, Bonny Estuary.

\section{INTRODUCTION}

Meiobenthos, also called meiofauna, are small benthic invertebrates that live in both marine and fresh water environments. They are important in any aquatic ecosystem and serve as a vital link between producer and consumer organisms. These organisms have an important role to play in the ecosystem, in that they are metabolically important members of benthic ecosystem (Gerlach, 1971). They are also known to be prey for variety of larger animals particularly juvenile fishes (Coull et al, 1981). The meiobenthos includes many small copedpods, nematodes, flatworms, the larva stages of various molluses, polychaetes, copedpods and nematodes which are numerically most important.

Despite the important role played by meiofauna in the ecosystem and trophic organization, they also serve as pollution indicators and change detector in the environment (Gerlach, 1971 and Sibent et al., 1997). The ability of meiofauna to serve as pollution indicators is particularly useful in the investigation of pollution prone water bodies. Bonny River given its unique location and diverse human activities is one of such threatened and pollution prone water body.

Bonny River is an important River system east of the Niger. It serves as a major gateway to a number of industrial and commercial activities. Along the shores are located multinational companies that have established oil tank farm, liquefied natural gas, flow stations, several pipelines routes, crude oil farm loading bay, condensation plants, office and living quarters for their staff alongside the indigenous populations. It empties directly into the Atlantic Ocean.

The distribution of meiofauna in any natural or polluted environment is of much significance to scientist. This have provided major challenges to the scientific community due to the fact that information on meiofauna community is sparse despite the important role played in the ecosystem and trophic organization and their use as indicators of pollution and change detector in the environment (Gerlach, 1977 and Sibert et al., 1997). As Bonny River represents a very important and strategic water system, there is an urgent need to gauge its meiofaunal characteristic as to determine its pollution and changing status. This will provide useful information for all stakeholders as to the protection of the ecosystem and to safe-guard its fishery. 


\section{MATERIALS AND MeTHODS}

\subsection{Description of Study Area.}

The lower Bonny River is located southeast of the Niger Delta between longitudes $7^{0} 05^{\prime} \mathrm{E}$ and $7^{0} 20^{\prime} \mathrm{E}$ and latitude $4^{0} 10^{\prime} \mathrm{N}$ and $4^{0} .40^{\prime} \mathrm{N}$. The Bonny River system consists of the main river channel of the Bonny River and large number of associated creeks and creeks-lets.

\subsection{Description of Sampling Stations}

TABLE 1

DESCRIPTION OF SAMPLING STATIONS

\begin{tabular}{|c|c|}
\hline Stations & Description \\
\hline 1 & Fuel depot \\
\hline 2 & House-hold waste refuse dump. \\
\hline 3 & Fishing settlement/activities \\
\hline 4 & Living quarters/Settlements \\
\hline 5 & Up stream of Estuary (Control) \\
\hline
\end{tabular}

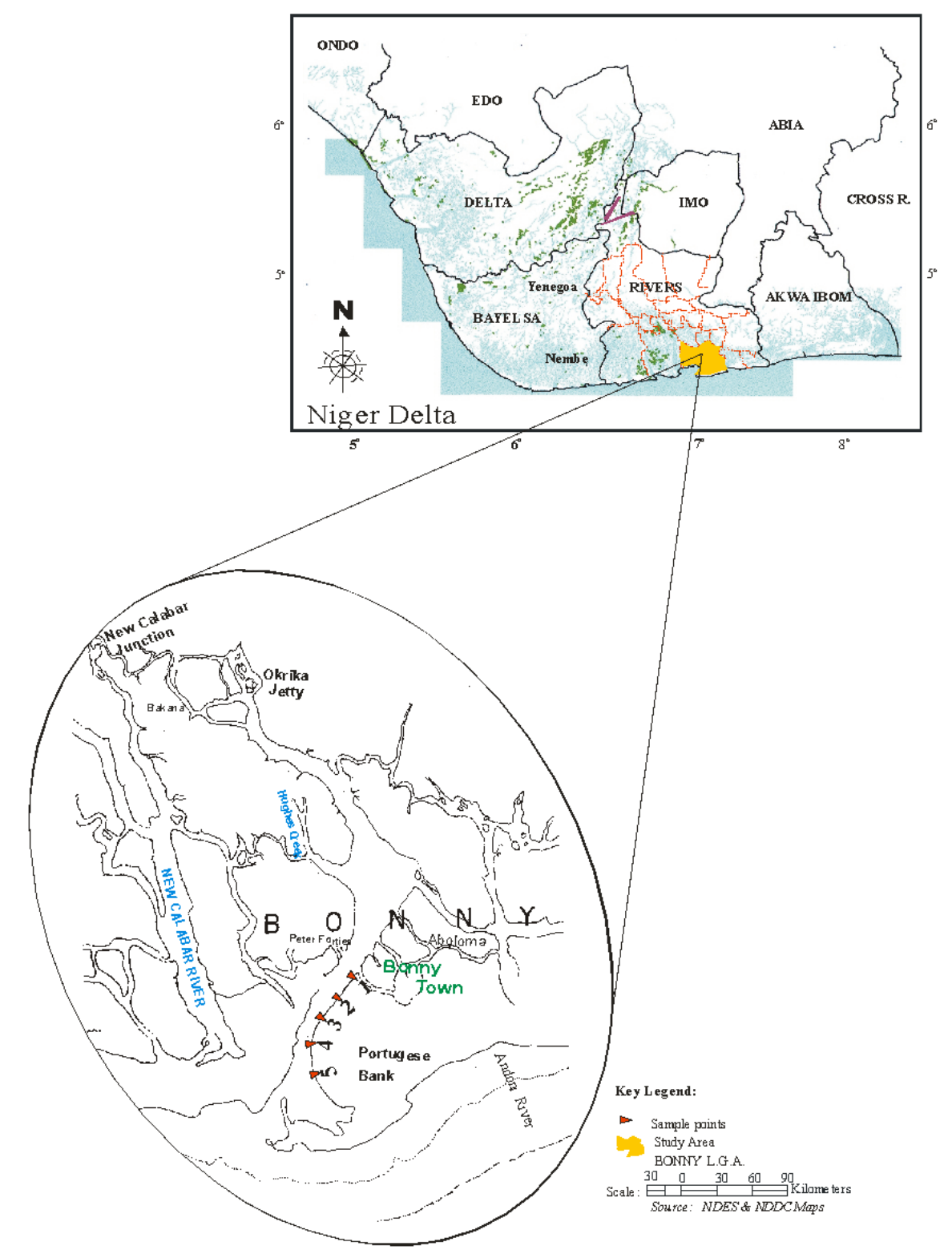

FIG.1: MAP OF NIGER DELTA SHOWING BONNY ESTUARY IN BONNY LGA 


\subsection{Sample Collection (Sediment/Meiofauna)}

Sediment samples for both meiofauna and sediment size analyses were collected at low tide with the aid of soil auger within the littoral zone. Collected samples were wrapped in Aluminum foil and stored in an ice cool chest before transport to the laboratory. This was done in triplicate for each sample station.

Sediment samples for meiofauna analyses were stirred through $(63-212 \mathrm{~nm})$ meshes to separate meiofauna from organic Debris. Meiofauna samples were processed by first washing Meiofauna through a sieve of fine mesh size made of silk material, in order to wash off excess silt or mud. The sieved samples were contained in vials and fixed with 5\% formalin after which rose Bengal was added. This was done to stain the organism red, to facilitate sorting of organisms. The samples were mounted on high powered microscope in the laboratory and identified using suitable keys.

\subsection{Data Analyses}

Percentage occurrence, species richness, evenness, dominance and relative numerical abundance of meiofauna were calculated using the Excel Descriptive Statistic Tools (EDST).

Diversity index analysis was calculated using the entire identified Meiofauna organism. The number of each individual of the identified groups is replicated during each sampling were summed up by species to obtain the total number of species at each station.

Diversity of the aquatic fauna was determined using the Shannon - Wiener index, equitability (E) of species (Ajao, 1990) and Margalef's diversity as follows:

Species richness by Margalefs(1967) formula:

$$
\mathrm{d}=(\mathrm{s}-1) / \mathrm{In} \mathrm{n}
$$

Where

$\mathrm{H}$ "= Species diversity; $\mathrm{E}=$ Evenness; $\mathrm{S}=$ Number of families; $\mathrm{n}=$ Total number of animal ni= Number of each family.

Diversity of the aquatic fauna were determined using Shannon - Weiner index, equitability (E) of species and Margalef's diversity

Shannon-weiner diversity index given by the formula:

$$
\begin{aligned}
& \mathrm{S} \\
& \mathrm{Hs}=1
\end{aligned}=\sum(\mathrm{Ni} / \mathrm{N}) \log 2(\mathrm{Ni} / \mathrm{N})(\text { Shannon }- \text { Weiner, 1963) }
$$

Where Hs = Shannon - Weiner information

$\mathrm{N}=$ Total number of individuals in the sample

Evenness (E) index shows how evenly the species are distributed in a sample community also called evenness index.

Equitability or Evenness by the formula:

$$
\mathrm{E}=\mathrm{H} " / \text { Ins }
$$

\section{ReSUlt (Meiofauna)}

\subsection{Relative Composition}

Meiofauna assemblages collected along the beach of lower bonny estuary were diverse and are represented in their major taxonomic groups (Tables 2 and 3). The results showed that the distribution of meiofauna varied from stations and season.

A total number of 16 species from 6 families of meiofauna were observed during the survey of the estuary. The predominant families were Linhomoeidae $(2.25-32.14 \%)$ of the entire population, followed by Desmodoridae $(14.61-28.57 \%)$ and Leptosomatidae (13.48 - 17.86\%). 
The leptosomatidae had a range of $(2.30$ - 32.14) and minimal variation was observed between stations with maximum and minimum values recorded in station 5 in the wet season and in station 2 and 4 for the study period. Seasonally, the wet season had high population composition than the dry period.

The plectidae had a range of $(10.34-17.86 \%)$ with station 2 and 5 having maximum values for the dry period and stations 3 and 5 having maximum population value in wet season.

The population of the Desmodoridae recorded showed that a maximum population was recorded in the dry season in 2 and 5 , while the least population was observed in station 3 and 2 for wet season while the population range was observed to be from $(14.94-28.57 \%)$.

\subsection{Species Richness}

The results of species richness using the Margalef's index (1967) showed that there were seasonal variations. The wet season value ranged from $(0.91-1.52)$ and $(1.44-2.98)$ for dry season. Therefore Species Richness was higher in the dry season.

\subsection{Species Diversity}

The results of the species diversity obtained from the different taxonomic groups using Shannon-wiener index showed uniformity in pattern between dry season and the wet season. The wet season values ranged from $(0.28-0.96)$ and $(0.30-$ $0.95)$ for dry season. This implies a lack of seasonal variation in species diversity.

\subsection{Species Evenness}

Species evenness during the study period ranged from $(0.89-1.00)$ for the wet season and $(0.84-1.00)$ for the dry season. There was no much difference in the values. Maximum and minimum values were observed in stations 3 and 5 respectively for both seasons. Species evenness had high values in wet season than in the dry season (Fig 4.)

\subsection{Species Dominance}

The species dominance for the entire study period ranged from $(0.27-0.56)$ for the wet season and $(0.19-0.33)$ for the dry period. This showed that there were slight variations across the seasons and stations.

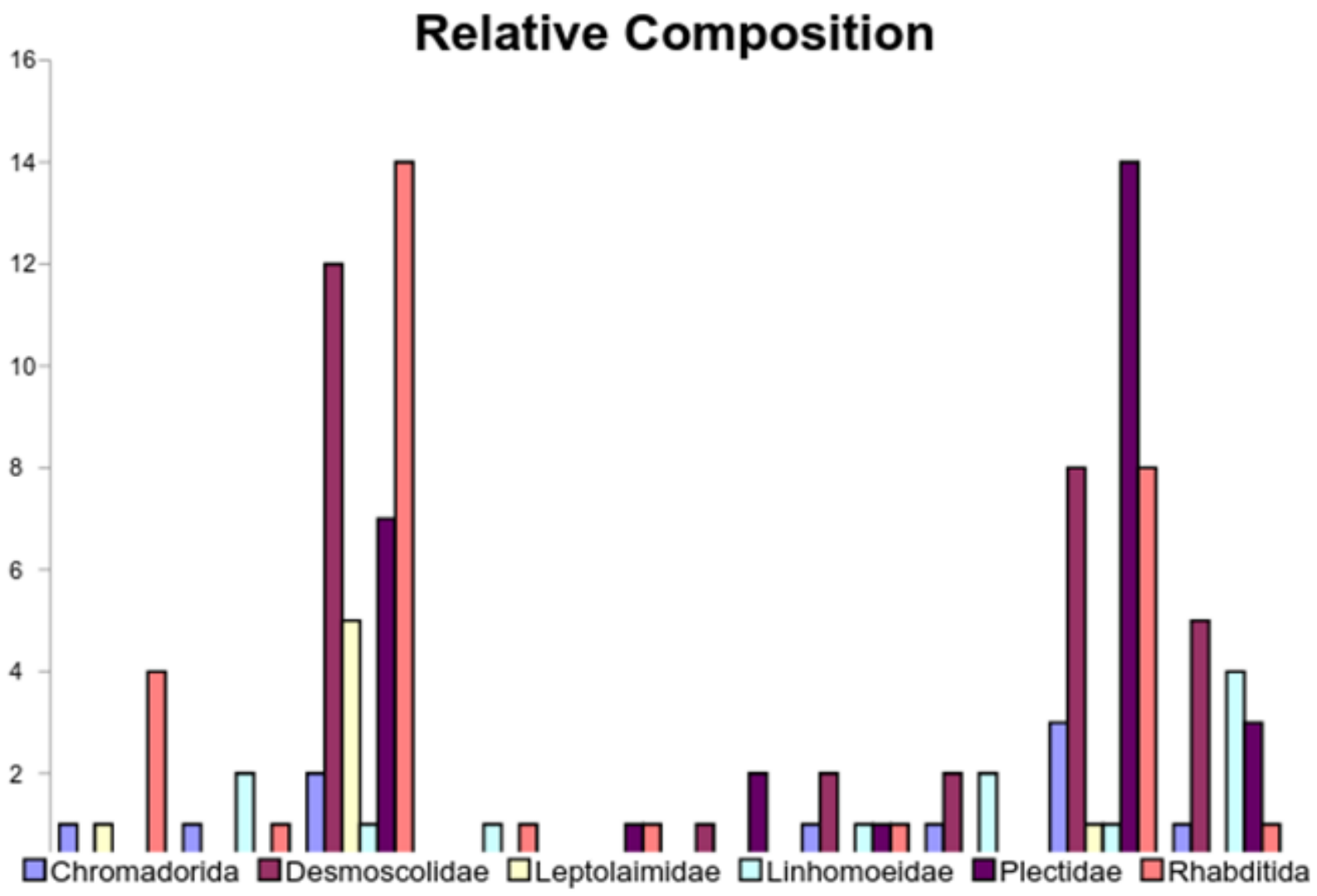

Fig. 2: Relative CoMposition OF Meiofuana 
TABLE 2

Distribution OF MEIOFAUNA AT THE FIVE STATIONS OF LOWER BONNY ESTUARY (WET SEASON).

\begin{tabular}{|c|c|c|c|c|c|c|c|}
\hline Family & Genus Spp & STN 1 & STN 2 & STN 3 & STN 4 & STN 5 & Total \% Dominance \\
\hline \multirow{3}{*}{ Chromadoridae } & Chromadorella Spp & 1 & $\mathrm{O}$ & $\mathrm{O}$ & 1 & 1 & 10.71 \\
\hline & Chromadorina Spp & $\mathrm{O}$ & $\mathrm{O}$ & $\mathrm{O}$ & $\mathrm{O}$ & $\mathrm{O}$ & $\mathbf{0}$ \\
\hline & Chromodorita Spp & $\mathrm{O}$ & $\mathrm{O}$ & $\mathrm{O}$ & $\mathrm{O}$ & $\mathrm{O}$ & $\mathbf{0}$ \\
\hline \multirow[t]{4}{*}{ Desmodoridae } & Diplolaimella Spp & $\mathrm{O}$ & $\mathrm{O}$ & 1 & 2 & 5 & 28.57 \\
\hline & Desmoscolex Spp & $\mathrm{O}$ & $\mathrm{O}$ & $\mathrm{O}$ & $\mathrm{O}$ & $\mathrm{O}$ & $\mathbf{0}$ \\
\hline & Desmolaimus Spp & $\mathrm{O}$ & $\mathrm{O}$ & $\mathrm{O}$ & $\mathrm{O}$ & $\mathrm{O}$ & $\mathbf{0}$ \\
\hline & Hliplectus Spp & $\mathrm{O}$ & $\mathrm{O}$ & $\mathrm{O}$ & $\mathrm{O}$ & $\mathrm{O}$ & $\mathbf{0}$ \\
\hline Leptolamidae & Hypodontolemus & $\mathrm{O}$ & $\mathrm{O}$ & $\mathrm{O}$ & $\mathrm{O}$ & $\mathrm{O}$ & $\mathbf{0}$ \\
\hline Linhomoeidae & Leptolaimus Spp & 2 & 1 & $\mathrm{O}$ & 2 & 4 & 32.4 \\
\hline \multirow{2}{*}{ Plectidae } & Prochomadora Spp & $\mathrm{O}$ & $\mathrm{O}$ & $\mathrm{O}$ & $\mathrm{O}$ & $\mathrm{O}$ & $\mathbf{0}$ \\
\hline & Paracytholaimus & $\mathrm{O}$ & $\mathrm{O}$ & 2 & $\mathrm{O}$ & 3 & 17.80 \\
\hline \multirow[t]{5}{*}{ Rhabdodemaniidae } & Sphacrolaimus Spp & $\mathrm{O}$ & $\mathrm{O}$ & $\mathrm{O}$ & $\mathrm{O}$ & $\mathrm{O}$ & $\mathbf{0}$ \\
\hline & Rhabdolaimus Spp & $\mathrm{O}$ & $\mathrm{O}$ & $\mathrm{O}$ & $\mathrm{O}$ & 1 & 3.57 \\
\hline & Thornilla Spp & $\mathrm{O}$ & $\mathrm{O}$ & $\mathrm{O}$ & $\mathrm{O}$ & $\mathrm{O}$ & $\mathbf{0}$ \\
\hline & Paractinolaimus & 1 & 1 & $\mathrm{O}$ & $\mathrm{O}$ & $\mathrm{O}$ & 7.14 \\
\hline & Rhabditis Spp & $\mathrm{O}$ & $\mathrm{O}$ & $\mathrm{O}$ & $\mathrm{O}$ & $\mathrm{O}$ & $\mathbf{0}$ \\
\hline Total & & & & & & & 100 \\
\hline
\end{tabular}

TABLE 3

DRY SEASON Distribution OF MEIOFAUNA AT THE FiVE STATIONS OF LOWER BONNY ESTUARY

\begin{tabular}{|c|c|c|c|c|c|c|c|}
\hline Family & Genus Spp & STN 1 & STN 2 & STN 3 & STN 4 & STN 5 & Total \% Dominance \\
\hline \multirow{4}{*}{ Chromadoridae } & Chomadorella Spp & 1 & 1 & - & $\mathrm{O}$ & 1 & $\mathbf{3 . 4 5}$ \\
\cline { 2 - 8 } & Chromadarina Spp & $\mathrm{O}$ & 1 & - & 1 & 1 & $\mathbf{3 . 4 5}$ \\
\cline { 2 - 8 } & Chromodorita Spp & $\mathrm{O}$ & $\mathrm{O}$ & - & 1 & 1 & $\mathbf{2 . 3 0}$ \\
\hline \multirow{3}{*}{ Desmoscolidae } & Diplomella Spp & $\mathrm{O}$ & 3 & $\mathrm{O}$ & 2 & 8 & $\mathbf{1 5 . 0}$ \\
\hline & Desmoscolex Spp & $\mathrm{O}$ & 8 & $\mathrm{O}$ & $\mathrm{O}$ & $\mathrm{O}$ & $\mathbf{9 . 0}$ \\
\cline { 2 - 8 } & Desmolaimus Spp & $\mathrm{O}$ & 1 & $\mathrm{O}$ & $\mathrm{O}$ & $\mathrm{O}$ & $\mathbf{1 . 1 5}$ \\
\hline \multirow{3}{*}{ Leptolamidae } & Hliplectus Spp & 1 & 3 & $\mathrm{O}$ & $\mathrm{O}$ & 1 & $\mathbf{5 . 7 5}$ \\
\hline \multirow{3}{*}{ Plectidae } & Hypodontolamus & $\mathrm{O}$ & 2 & $\mathrm{O}$ & $\mathrm{O}$ & $\mathrm{O}$ & $\mathbf{2 . 3 0}$ \\
\hline Rhabditidae & Laptolaimus Spp & $\mathrm{O}$ & 1 & $\mathrm{O}$ & 1 & $\mathrm{O}$ & $\mathbf{2 . 3 0}$ \\
\hline & Prochomadora Spp & $\mathrm{O}$ & 6 & $\mathrm{O}$ & $\mathrm{O}$ & 6 & $\mathbf{1 3 . 7 9}$ \\
\cline { 2 - 8 } & Paracytholaimus & $\mathrm{O}$ & $\mathrm{O}$ & 1 & $\mathrm{O}$ & 8 & $\mathbf{1 0 . 0}$ \\
\cline { 2 - 8 } & Sphacrodaimus Spp & $\mathrm{O}$ & 8 & $\mathrm{O}$ & $\mathrm{O}$ & 5 & $\mathbf{1 5 . 0}$ \\
\cline { 2 - 8 } & Rhabdolaimus Spp & 1 & 5 & $\mathrm{O}$ & 1 & 2 & $\mathbf{1 0 . 3 4}$ \\
\cline { 2 - 7 } & Thronella Spp & $\mathrm{O}$ & $\mathrm{O}$ & 1 & $\mathrm{O}$ & $\mathrm{O}$ & $\mathbf{1 . 1 5}$ \\
\cline { 2 - 7 } & Paractinolaimus & $\mathrm{O}$ & 1 & $\mathrm{O}$ & $\mathrm{O}$ & 1 & $\mathbf{2 . 3 0}$ \\
\hline Rhabditis Spp & 3 & $\mathrm{O}$ & $\mathrm{O}$ & $\mathrm{O}$ & $\mathrm{O}$ & $\mathbf{3 . 4 5}$ \\
\hline & & & & & & & $\mathbf{1 0 0}$ \\
\hline
\end{tabular}

\section{DISCUSSION OF RESULTS}

In this study, nematodes were the only meiofauna group observed. Most species of nematode have a direct development phase and a short life-cycle of one to three months. Therefore, changes in the community structure can be readily observed in short-term studies like this one. 
The results reveal a trend that is difficult to understand and explain as there appear to be no significant difference in faunal characteristics such as diversity, abundance, richness and evenness across the various sampling stations (stations 1 - 4) except between the upstream station (station 5) and others. This may be due to the constant interaction of causal factors as the estuary is constantly navigated by marine crafts. Therefore, the application of biodiversity indices based on higher taxonomic resolution does not seem to yield higher discriminatory power in evaluating environmental quality when the ecosystem is in constant flux.

This lack of a large spatio-temporal variation in meiofauna may also be as a result of lack of changes in food supply correlations between any of the indicators and the concentrations of total protein, which represent the fraction of organic matter available for these benthic consumers (Vezzulli and Fabiano, 2006). The study also recorded fluctuating meiofaunal diversity with highs in some stations and lows in others. This may be due to the sensitivity of certain nematodes to certain pollutants. Very low species richness at this site is consistent with high sediment toxicity, while the moderate abundances and biomasses recorded may be explained by the ability of a few species to benefit from the eutrophic conditions of the estuary.

Warwick (1988) suggests that anthropogenic effects modify benthic community composition at relatively high taxonomic levels, while natural environmental variables influence the fauna more by species replacement.

Consistent with this generalization, our results demonstrate that meiofauna assemblages in Bonny estuary show shifts in meiofauna community composition, especially the relative abundances of nematodes in response to anthropogenic alterations of estuarine habitat quality rather than natural environmental variability.

The presence of sensitive or tolerant meiofaunal taxa and nematode genera appears to be particularly informative in highlighting the state of sediment pollution and allows the use of other tools of assessment of the spatial heterogeneity of environmental disturbance within the estuary. However, the emphasis on sediment pathways as the primary means of Meiofauna recruitment is no longer appropriate since a number of recent studies have shown quite convincingly that both adult and juvenile meiofauna are regularly found in the water column (Ajao, 1990).

The absence of sub-surface water analyses data of meiofauna in this study, confines our explanation.

In conclusion, higher species diversity were observed upstream than downstream of the creek. This may be due to the fact that upstream stations are far removed and shielded from land based stressors. This has confirmed the assertion that land based activities greatly affect aquatic integrity.

\section{REFERENCES}

[1] Ajao, E.A (1990) The influence of domestic and industrial effluents on populations of sessile and benthic organisms in Lagos lagoon. Ph.D Thesis, University of Ibadan, Nigeria, $413 \mathrm{pp}$

[2] Coull, B. C., G. R. F. Hicks and J. B. J. Wells. 1981. Nematode/copepod ratios for monitoring pollution: A rebuttal. Mar. Pollut. Bull.12:198-381.

[3] Gerlach, S. A. 1971. On the importance of marine meiofauna for benthos communities. Oecologia 6: 176-190.

[4] Margalef, R. (1967). Diversity and stability: A practical proposal and a model of

[5] Inte-rdependence. Brookhaven. Sympo. Biol., 22: 2537.

[6] Shannon, C.E., Weaver, W. 1963. The mathematical theory of communication. University of Illinois, Urban Press, Illinois. 177Pp

[7] Sibert, V., B. Zakardjian, F. Saucier, M. Gosselin, M. Starr, and S. Senneville (2010), Spatial and temporal variability of ice algal production in a 3D ice-ocean model of the Hudson Bay, Hudson Strait and Foxe Basin System, Polar Res. 29, 353-378, doi:10.1111/j.1751-8369.2010.00184.x.

[8] Vezzulli, L., and Fabiano, M. (2006) Sediment biochemical and microbial variables for the evaluation of trophic status along the Italian and Albanian Continental Shelves. Journal of the Marine Biological Association of the UK, 86: 27-37.

[9] Warwick, R. M. 1981. The nematode-copepod ratio and its use in pollution ecology. Marin Pollution Bulletin, 12: 329-333. 